\title{
MASCULINIDADES PÚBLICAS NA PRINCESA DO SERTÃO: COMPORTAMENTOS E PERFIS DE HOMENS DURANTE A PRIMEIRA REPÚBLICA EM CAXIAS/MA
}

\section{ARTIGO ORIGINAL}

RIBEIRO, Jakson dos Santos ${ }^{1}$

RIBEIRO, Jakson dos Santos. Masculinidades públicas na Princesa Do Sertão: Comportamentos e perfis de homens durante a Primeira República em Caxias/MA. Revista Científica Multidisciplinar Núcleo do Conhecimento. Ano 05, Ed. 12, Vol. 07, pp. 75-91. Dezembro de 2020. ISSN: 2448-0959, Link de acesso: https://www.nucleodoconhecimento.com.br/historia/princesa-do-sertao

\section{RESUMO}

O presente texto objetiva analisar a enunciação das masculinidades públicas durante a experiência da Primeira República na cidade de Caxias, Maranhão a luz da imprensa da cidade. Desse modo, o objetivo da pesquisa é problematizar os discursos e suas implicações na definição desse modelo de masculinidade em Caxias. Para o desenvolvimento da pesquisa, utilizou-se a metodologia da análise do discurso, elencando os sentidos da palavra e os significados sociais. Nesse sentido, identificamos que essas práticas de masculinidades, foram resultados das estratégias discursivas constituídas nas teias representativas da imprensa caxiense, articulada ao projeto de nação e cidadão, às noções de progresso, corpo e cidade marcadas pelo gênero. Assim, ao longo dessas análises, identificamos como resultado, que tais masculinidades construídas discursivamente, estavam em diálogo com as vivências

${ }^{1}$ Doutor em História Social da Amazônia - UFPA, Mestre em História Social - UFMA, Especialista em História do Maranhão - IESF, Graduado em História - UEMA, Graduado em Pedagogia - UNICID. 
masculinas cotidianas do contexto caxiense pertencentes a nossa reflexão históricosocial.

Palavras-chave: Discurso, imprensa, masculinidade, ideal.

\section{INTRODUÇÃO}

Ao pensar na dimensão da imprensa, notamos que os "o jornal, a revista e o cartaz veículos de palavra impressa - potencializavam consumo de toda ordem. Apesar desses avanços, a imprensa brasileira ainda estava longe de sua "fase de consolidação" como destaca Juarez Bahia e mesmo da "grande imprensa", como afirma Nelson Werneck Sodré.

Por essa via, ao pensar na imprensa caxiense durante a Primeira República, buscamos evidenciar em nossas análises, as questões voltadas ao cotidiano da cidade de Caxias, em tempos republicanos, como também os discursos que circulavam sobre as formas de pensar os conceitos de masculinidade e homens públicos. Nesse compasso é importante salientar que essas masculinidades se apresentavam dentro de uma premissa de ordem (ideal) e desordem (real). Um fator possível de ser percebido a luz das representações desses discursos e imagens presentes nesses periódicos. Por isso, Roger Chartier nos aponta que:

[...] primeiramente, as operações de recorte e de classificação que produzem as configurações múltiplas graças às quais a realidade é percebida, construída, representada; em seguida, os signos que visam a fazer reconhecer uma identidade social, a exibir uma identidade própria de estar no mundo, a significar simbolicamente um estatuto, uma ordem, um poder; enfim, as formas institucionalizadas através das quais 'representantes' encarnam de modo visível, 'presentificam', a coerência de uma dada comunidade, a força de uma identidade, ou a permanência de um poder. (CHARTIER, 2002, pp. 61-80).

Nesse sentido, podemos pensar como o jornal, O Paiz, aborda por exemplo, a o papel do jornalista no desenvolvimento das informações.

O jornalista tem na sociedade uma influência muito mais profunda que a do mestre escola e responsabilidade muito mais graves. É o jornal que 
refere e que explica ao povo as diferentes phenomenos de sua vida política, de sua vida social, da sua vida econômica.

É o jornal que faz a crítica das instituições e dos costumes.

É o jornal que estabelece o critério por que tem de ser julgados factos da vida civil e da vida moral.

É o jornal que fixa para a multidão o ponto de vista nas altas questões da honra, da dignidade e do dever. (JORNAL O PAIZ, 26 de junho de 1904, Anno II, número 75, p.03).

Nesse caso, os discursos são moldados para que não sejam infiltrados por interpretações outras, pois isso poderia inviabilizar o próprio jogo de interesses pelos quais os produtores desses discursos lançam sobre esse jogo linguístico. A ideia é fazer com que tais discursos estejam enquadrados em espaços isolados quanto a significados múltiplos, ou seja, ao protegê-los de infiltração pelas entoações próprias ao autor, isso simplifica e consolida as características linguísticas individuais, como os próprios interesses dos produtores desses discursos.

Para Bakhtin, os discursos são influenciados pelas condições econômicas dos grupos sociais que os emitem. Em cada época, esses aspectos devem ser levados em conta, pois são pontos de medidas para avaliar o grau de interesses inseridos nas teias discursivas dos discursos produzidos. Nesse sentido, a língua registra "as impressões do discurso de outrem e da personalidade do locutor, os tipos de comunicação sócio ideológica em transformação no curso da história manifestam-se com um relevo especial”. (BAKHTIN, 2006, 157).

Sócrates Nolasco (1993), quando pensa sobre a ideia de violência posteriormente a esta realidade que estamos analisando, nos traz contribuições importantes para discutirmos, por exemplo, como a validade social da "agressão se transformou para os homens em sinônimo de iniciativa. Incorporada às suas identidades, agressão passou a ser, para um homem, elemento de constituição que, sobreposto à virilidade, produz os "machões." (NOLASCO, 1993, p. 76).

A maneira como a República se materializou no Brasil, em seus anos iniciais, talvez seja realmente constituída como bem nos apontou José Murilo de Carvalho, em sua 
obra Os Bestializados, embora essa bestialização tenha sido experienciada de diversas formas, principalmente no desejo de ser uma República. Assim, ao folhear as páginas dos jornais caxienses para decifrar os comportamentos, os perfis masculinos, as questões de gênero relacionadas ao mundo dos homens e suas interseccionalidades, percebi o quanto os discursos republicanos se faziam presentes, principalmente intercalados entre os desejos de manifestar uma nação ideal.

Como afirma Durval Muniz de Albuquerque, dentro do cotidiano, as práticas de gênero, das maneiras "[...] de ser homem não estão determinadas nem pela genitalidade, nem pelos códigos de sexualidade. O gênero nem é natural, sendo uma criação histórica e cultural, nem está preso completamente a uma ordem dominante de prescrições." (ALBURQUERQUE JUNIOR, 2003, p. 08).

Nesse caso, o ideal republicano constituído dentro da Primeira República manifestouse de diversas maneiras no Brasil. Isso devido à própria dimensão do país, como também às formas de comunicação naquele contexto, pois mesmo com renovação das tipografias ainda era possível verificar lugares cuja produção de jornais utilizava técnicas rudimentares. Isso, no entanto, não inviabilizou que a imprensa fosse utilizada como interlocutora dos ideais republicanos. Mediante essa questão, analisando os discursos proferidos pelos idealizadores da Nação Ideal, essa pesquisa - entrelaçada com teorias de gênero, em especial com os estudos voltados para compreender as representações acerca da figura do homem e as performances masculinas - busca-se entender como a imprensa caxiense representava qual era o ideal de masculinidade ao longo das páginas dos principais jornais, o ideal de homem que deveria se apresentar no jogo social da cidade naquele contexto.

Visto que, ao caminhar pelas páginas desses jornais que circularam em Caxias durante a Primeira República, percebe-se uma forte representação das maneiras ideais, de como esse homem deveria se comportar no regime republicano que aflorava no país, principalmente quando percebe-se que os periódicos buscavam salientar quais as posturas aceitáveis nos logradouros públicos, nos espaços de sociabilidade e, ainda, quais os princípios relacionados à ideia de homem honrado que deveriam coexistir com esse homem dentro das suas relações sociais, além de 
reforçar o cuidado com seu alto controle diante de desentendimentos, ocasionados por motivos diversos.

Por isso, nota-se que buscava-se imprimir na cena social, a partir das práticas dos indivíduos, a noção de ordem e desordem, o que denota nessa perspectiva os objetivos de construir uma cidade moderna a fim de contribuir para alcançar o progresso e desenvolvimento do país naquele momento.

Desse modo, podemos perceber que a imprensa buscava apresentar a existência de dois tipos de perfis: o primeiro são os sujeitos que apresentamos na nota utilizada no começo dessa discussão, representa os homens pertencentes aos segmentos populares - esses, aos olhos da imprensa, são sujeitos vistos como indivíduos desordeiros, como um contra modelo aos ideais de ordem e progresso tão exaltados no período da Primeira República.

Nesse caso, ao olharmos os jornais pesquisados, referentes à primeira República, em Caxias/Ma, percebemos que Caxias, representada nessas páginas, é uma cidade do progresso, da ordem, da disciplina, do desenvolvimento, e, ainda, uma cidade que aflora através dos discursos uma diversidade de comportamentos que se entrelaçam entre os comportamentos ditos e entendidos como ideais, como também entre aqueles compreendidos e entendidos como contraventores.

O procedimento supõe que distancia seja tomada em relação aos princípios que fundavam a história social da cultura em sua acepção clássica. Uma primeira variação foi marcada ante uma concepção estreitamente sociográfica que postula que as clivagens culturais são organizadas necessariamente de acordo com um recorte social construído previamente. É necessário, creio, recusar essa dependência que relaciona as diferenças nos hábitos culturais oposições sociais dadas a priori, seja na escala de contrastes macroscópicos (entre as elites e o povo, entre os dominadores e os dominados), seja na escala de diferenciações menores (por exemplo, entre os grupos sociais hierarquizados pelos níveis de fortuna e as atividades profissionais. (CHARTIER, 2002, p. 70).

A Princesa do Sertão, conforme os discursos apresentam através da imprensa, pelos jornais, é uma cidade que também vivia os males de ser um centro de expressividade 
econômica, pois os problemas como falta de segurança são elementos que se faziam presentes no perímetro da cidade.

Os discursos produzidos, nestas páginas, imprimem uma identidade que envereda pelos trilhos do desenvolvimento, mas que não deixa de vivenciar os princípios da boa moral. Caxias é uma cidade em que as pessoas vivenciam os princípios religiosos e, mais ainda, praticam os ensinamentos que são apresentados por um discurso, religioso.

As formas de enunciação dos discursos devem ser levadas em conta, porque a tendência analítica do discurso indireto manifesta-se pelo fato de que os elementos emocionais e afetivos, que também estão presentes na constituição desses discursos, "não são expressos no conteúdo, mas nas formas da enunciação". (BAKHTIN, 2006, p. 199). Assim, Bakhtin chama a atenção sobre o peso das palavras, elas agem e interagem em sentidos múltiplos, devido à força de significação caracterizadora, que se reforça, da mesma forma que sua tonalidade ou seu valor típico.

Nesse caso, a preparação do citado ganha contornos na narração, a tal ponto que pode dar ao contexto narrativo feições e tonalidades em que o discurso citado, embora conservando as entoações próprias do autor, vai conduzir a narrativa exclusivamente dentro dos limites da ótica.

O sentido do discurso transcorre construído sobre a perspectiva de dar ao sujeito contribuições, que, segundo os produtores desses discursos, são "essenciais" para os sujeitos no espaço social em que estão inseridos. "O destino da palavra é o da sociedade que fala". (BAKHTIN, 2006, p. 199). A palavra dentro do discurso é um fenômeno ideológico por excelência, e acompanha o desenvolvimento da cidade e modernidade que se estabelece no espaço citadino.

Assim, podemos acrescentar que os discursos possuem um poder disciplinar que possibilitam a fabricação de uma realidade, de uma subjetivação de sujeição. Os discursos funcionam como dispositivos que se fazem existir enquanto prática. 


\section{O HOMEM PÚBLICO O HOMEM DA CIDADE}

A formação educacional entre os membros da elite se tornou ao longo do processo de criação das distinções sociais, um vetor para imprimir, no bojo social, aspectos de diferenciações entre os detentores do poder e os chamados segmentos populares. Os meninos da elite tinham destino certo para formação como médicos e advogados. Tais profissões detinham, principalmente, nesse contexto da República, um aspecto de afirmação das capacidades desses homens em assumir tarefas no espaço público.

Desta forma, ser advogado, por exemplo, seria possuir um capital simbólico e cultural expressivo, pois representava alcançar um status diferenciado quanto aos demais homens da sociedade. Um fato preponderante no imaginário social brasileiro, mas que foi importado da Europa para realidade do Brasil.

Nesse caso, a importância dada à educação pelos segmentos mais abastados da sociedade era feita de maneira expressiva, pois significava reforçar a distinção social diante dos demais. O poder público estaria bem e, mais ainda, a elite estaria bem, se ela estivesse constituída de moços formados para assumir cargos constituídos de significação social e poder diante da sociedade.

Em Caxias, por exemplo, quando se tinha a notícia que um novo advogado ou médico havia alcançado a formação, ou seja, conseguido o diploma, existiam homenagens na imprensa por outros advogados, fazendo referência a esse novo homem pertencente ao mundo das leis.

\section{Bacharel}

Acaba de receber o grao de bacharel em Direito pela Faculdade em Recife nosso talentoso amigo José Martins de Freitas, que já se acha na capital deste Estado de viagem para cá. Anciosos o esperamos, como o esperam também seu ilustre que Dr. Jesuino Freitas e Exmª . Família aos quaes comprimentamos pela intensa alegria de saberem haver chegado ao termino da vida academia este moço distincto, que vae entrar na vida prática sendo portador de um nome responsável.

Saudações ao Bacharel e ilustre Família. (JORNAL GAZETA CAXIENSE, 22 de dezembro de 1893, Ano VII, número 86, p. 02). 
Os jovens caxienses que se destacavam eram apresentados pela imprensa enquanto modelos a serem seguidos, os filhos dos membros da elite que saíam para estudar nos principais centros, por exemplo, Recife, eram referenciados como símbolos da maneira ideal de como os demais jovens deveriam entender o seu papel enquanto cidadãos. O intuito, ao que notamos pelas notícias acima mencionadas, dava-se conforme um espectro para se pensar uma nação de homens sábios, capazes de dirigir o país sobre pulso da ordem e do bem-estar.

Os homens brasileiros que aderiram tanto ao coronelismo quanto ao tenentismo têm perfis bastante semelhantes, mesmo em se tratando de dois momentos diferentes na história. Em ambos, o fio condutor para composição das identidades sociais estava comprometido com a acumulação com a acumulação de bens e o prestigio social. (NOLASCO, 1993, p. 93).

Nesse caso, quando o jovem se tornava um homem das letras, um homem das leis, $\mathrm{O}$ jornal ainda publica que os feitos do jovem bacharel não cessaram, sendo ainda mais exaltado pela imprensa local. Por essa perspectiva, o jornal apresenta uma página com os louvores de boa sorte desejados por outros advogados da cidade.

Nesse caso, o jornal Gazeta Caxiense publica a homenagem, naquele momento, ao Dr. José Martins de Freitas, que foi inserido, a partir da diplomação, ao grupo seleto dos homens com destaque social, por causa da sua formação. Lembrando que os bacharéis foram vistos como homens de destaque, visto ao prestígio constituído às profissões de advogado e de médico. Na ocasião, ele é exaltado por ter aprimorado as suas faculdades mentais, em que o mesmo, segundo o jornal, cultivou de maneira muito expressiva seus potenciais.

O Dr. José Martins Freitas, que acaba de ser honrado pela Faculdade de Direito do Recife, é um desses poucos jovens, que reúnem a uma inteligência vigorosa e bem cultivada as virtudes cívicas que tanto nobilitam e engradecem o homem na sociedade.

Caracter grave, reflectido e recto, o jovem Bacharel já se tem revelado, nos poucos actos de sua pública o homem [...] 
Seja, pois bem entre nós [...] de cujos serviços muito espera o futuro da Pátria. (JORNAL GAZETA CAXIENSE, 01 de janeiro de 1894, Ano VIII, número 89, p. 01).

Percebe-se que José Martins Freitas conseguiu respaldo, dentro do jogo social, diante dos demais indivíduos pertencentes ao grupo, o que ressalta o valor da masculinidade desse sujeito. A ideia de manter-se interligado aos princípios da boa conduta do indivíduo, que acalentou seus momentos com os estudos, era para sociedade caxiense um fator de muita importância para que os jovens, homens, senhores do amanhã, pudessem sentir o peso da responsabilidade de ser homem e suas obrigações enquanto homem público.

Muitos haviam abraçado a vida literária e acadêmica como alternativas à debacle da econômica da família. Outros tiveram no serviço público a única saída para, aproveitando-se de seu capital simbólico, se manterem uma subjetividade preparada isso. (ALBUQUERQUE JÚNIOR, 2013, p. $57)$.

Durval Muniz de Albuquerque Junior (2013) aponta que, na Primeira República, em que a classe dominante buscava cada vez empenho em mostrar-se moderna, era notório o envio dos jovens rapazes para estudar fora do país, ou mesmo em instituições dentro do país, como as escolas técnicas, faculdades de direito e medicina. O que demonstra nesse percurso, por parte desses membros da elite que mantinha,

[...] uma preocupação crescente de dar aos rapazes uma educação condizente com uma nova realidade social, de uma economia assentada na indústria, na técnica e no trabalho livre e assalariado. (ALBUQUERQUE JÚNIOR, 2013, p. 54).

Assim, em outro momento, o jovem advogado é comparado com a própria espada da justiça utilizada pelos militares para sustentar a honra do país, assim nota-se que o ideal masculino é projetado dentro das premissas da boa profissão escolhida pelos jovens. Nesse caso, como aponta Rayanne Connell, as masculinidades são configurações de práticas, ou seja, dentro do espaço social o indivíduo em questão possuía práticas que respaldariam sua ação social, mas que não são únicas, pois 
essas práticas podem ser diferentes, principalmente, por causa do espaço, em que tais práticas são efetivadas.

Nesse viés, aos olhos dos outros homens, de outros advogados que escreveram palavras de boas-vindas ao mais novo bacharel, como sinônimo de passagem do homem inexperiente, para homem maduro e mais responsável, com a vida adulta.

Si a Patria tem necessidade da espada militar para sustentar a honra nacional e a sacrossanto pendão da liberdade tão menos precisa da espada da justiça manejada pela mão firme de um recto e integro soldado lei se qual pertence firmar a paz e a harmonia do seio dos povos das diversas classes sociaes.

E assim a Patria deve exultar quando vê mais um filho seu apto e disposto a distribuir dignamente, a justiça, elevando a aos olhos do mundo que admira e respeita.

Dr. Freitas que acaba de ser laureado como o diploma de bacharel pela faculdade do Recife prestará ao seu paiz relevantes serviços porque é moço inteligente e patriota.

Render preito e homenagem aos caracteres severos e às conviç̧ões firmes, longe de ser lisonja interesseira, é obrigação de todos quantos reconhecem predicados.

O Dr. Freitas, pois moço ainda, tem deante de si um futuro que the sorri brilhante e venturoso e vira a ser certamente, um dos principaes ornamentos da masgistratura brazileira ou distincto patrono dos direitos postergados, grande se principalmente pelos precedentes do seu ilustre e respeitável pregenitor.

Aceite, assim o Dr. José Martins as nossas congratulações pela nação do seu tirocínio escholar e pelos seu regresso ao seio de sua familia extremesa e cumulada de saudades.

Eduardo de Berredo (Dr). (JORNAL GAZETA CAXIENSE, 01 de janeiro de 1894, Ano VIII, número 89, p. 01).

Ao identificar as adjetivações lançadas para homenagear o recém-advogado, notamos que ele institui um modelo de masculinidade existente no âmago da elite caxiense. É possível perceber qual era a importância da formação dos jovens em cursos de renome naquele contexto, como o curso de direito, principalmente, porque sua formação foi realizada na Faculdade de Direito de Recife. Nesse período da Primeira 
República, o caso do Dr. José Martins Freitas revela o quão a masculinidade alicerçada nas características de homem branco, católico e letrado tinha validade social para imprimir a esses homens status de homens ideais. Desse modo, Muniz aponta que:

[...] uma identidade pessoal que tende a reproduzir modelos e lugares de sujeito previamente definidos, passa-se para a sociedade burguesa, em que cada subjetividade deve ser lapidada no sentido de se tornar autônoma e diferencial em relação aos modelos da tradição. (ALBUQUERQUE JÚNIOR, 2013, p. 33).

Nesse sentido, as práticas que ressaltam as conquistas do jovem advogado, configurou no imaginário social caxiense, o indivíduo que incorporou as características do perfil de masculinidade ideal para ser visto, idealizado, e entendido como modelo para os demais. Em vista da divulgação das boas impressões, dos modelos de masculinidade, percebemos que os jornais caxienses buscavam trazer à tona todos os comportamentos que poderiam influenciar na constituição de modelos para outros homens.

Assim, podemos perceber, em um exemplo noticiado pelo jornal Gazeta Caxiense, em que o representante das leis é desenhado pelas palavras que fazem referências a ele, com as mais sublimes palavras que possam denotá-lo como um modelo de masculinidade para os homens caxienses.

\section{Dr. Rodrigo Octavio}

Há dias acha-se nesta cidade este nosso particular amigo, que acaba de ser nomeado promotor público de S. José dos Mattoes onde, de certo, saberá grangear as grandes sympathias que soem attrahir os caracteres se sua tempera.

Dispondo de uma inteligência vivaz e de apreciáveis virtudes cívicas, não se tendo ainda emmranhados nas pequenas nas pequenas intrigas dessa politicagem torpe que tanto deteriora os sentimentos humanos, o Dr. Rodrigo é hoje uma das mais firmes esperanças da Patria, que muito e muito necessita dos esforços, independia e actvidade de seus brilhos no momento angustioso em que encontramos.

Ao digno moço abraçamos affectuosamente. (JORNAL GAZETA CAXIENSE, 01 de junho de 1894, Ano VIII, número 131, p. 02). 
Em casos bem-sucedidos de homens que lidam com as leis, como advogados e magistrados, estes são intensamente apontados pelos jornais caxienses enquanto sujeitos de boa índole, sendo assim percebermos que eles são vistos como modelos, capazes de resolver os problemas da cidade. Acerca dessa premissa, podemos usar as considerações de Michel Kimmel, na qual o autor, ao pensar na chamada masculinidade hegemônica, considera que ela se manifesta e pode ser entendida no jogo social. Nesse caso, tal masculinidade se constrói no processo de oposição, ou seja, criando elementos que são exaltados como formas de creditar ao homem ideal um certo respaldo, por isso percebemos sempre palavras que evidenciam as qualidades desse homem.

Para um ideal de masculinidade que se confundia com a própria imagem positiva da sociedade burguesa, onde qualidades como autocontrole, disciplina, força, iniciativa, coragem, responsabilidade etc., definiam as virtudes sociais em si, quaisquer agentes que não estivessem dentro dos padrões estipulados destacavam-se como bizarros estranhos e perigosos. (OLIVEIRA, 2004, p. 78).

Por isso que, em outro momento, o jornal considera relevante frisar que a cidade precisava de homens capazes de auxiliar no bem estar que era a "pacata e moralisada" Caxias, pois infelizmente existiam homens que não corroboravam para manutenção da tranquilidade do povo, como era o caso da vinda de Rodrigo Octavio.

O jornal fazia menção ao português que estava residindo na cidade há cinco anos, mas que insistia em constituir a desordem dos caxienses. Segundo a notícia, o estrangeiro era bastante conhecido, onde no espaço citadino poucas são "[...] as pessoas em Caxias que não conhecem como um turbulento, um desordeiro, um perturbador do socego público, um desrespeitador da moral, um inimigo da honestidade." (JORNAL GAZETA CAXIENSE, 12 de junho de 1894, Ano VIII, número 136, p. 02).

Nesse caso, conforme as práticas do estrangeiro português, que estava em Caxias, esse era visto como o sujeito que descumpria as prerrogativas do bom homem, o mesmo apresenta ações que são vistas e reprovadas pela sociedade caxiense, o que denota, segundo Bourdieu, ser um corpo que estar no mundo social, porém esse 
mundo social não estar no seu corpo, ou seja, são regras e costumes dele que são contrárias ao pensamento da cidade nesse contexto.

Por essa ótica, Oliveira, considera que o habitus masculino é um conhecimento em que o homem adquiri e estar inscrito no corpo do mesmo e vai sendo expresso em suas condutas, atitudes e comportamentos, resultando ao final como um capital simbólico. Desse modo, ao pensarmos o habitus constituído entre o homem das leis, o promotor, o jovem advogado e o português desordeiro, identifica-se que em relação as descrições constituídas acerca deles nas páginas do jornal, observamos que o habitus de cada um foi instituído de maneira diferente.

Nessa via de compreensão, Oliveira (2004) aponta que, ao se pensar na constituição de um habitus masculino, "[...] oriundo do campo das relações de gênero, reproduzido nas vivências interacionais da masculinidade e (in) formado pela inserção social do agente, é postular que os comportamentos dos agentes, no caso os homens, de um modo geral refletirão aspectos dessa inserção." (OLIVEIRA, 2004, p. 220).

Nesse sentido, a chamada virilidade, considerada como verdadeira, estaria condicionada ao promotor, ao jovem advogado, pois pela ótica da ideia de trabalho eles apresentam aspectos incontestáveis, além de serem aprovados aos olhos da sociedade caxiense, pois apresentam sucesso em suas carreiras e, principalmente, reproduzem vivências que dialogam com os interesses dos membros adoradores da moral e bons costumes. Por isso ao olhar os elementos do capital simbólico, em que se proteja em relação a imagem desse indivíduo, os discursos não buscam evidenciar a sua sexualidade, mas as suas práticas.

Nessa perspectiva das ações, o que qualifica o homem ideal, suas práticas de homem benevolente também eram vistas aos olhos da imprensa caxiense como, por exemplo, o caso abaixo onde o senhor publiciza suas ações aos doentes residentes na Câmara Municipal de Caxias.

Caridade. Registramos com satisfação a ação caridoza praticada pelo sr. Antoniò Carlos da Cunha para com o doente Claro Pereira Júlio, em tratamento na caza da câmara. Aquelle cidadão deo um colchão para 
forrara meza que servia de leito ao enfermo desde o dia da operação. Em nome do pobre homem agradecemos tão grande esmola. Quem dá aos pobres empresta a Deus. Aproveitamos o ensejo para pedir as pessoas caridozas, aos que têm pena dos que soffrem, uns pannos velhos para curativos das feridas do pobre Claro. (JORNAL GAZETA CAXIENSE, 25 de abril de 1893, Ano VII, número 19, p. 02).

Ao ver a maneira como o jornal aponta acerca da ação de Antonio Carlos, em relação ao outro homem, enfermo, nota-se que as palavras constroem a imagem do modelo benevolente, uma condição da masculinidade vista como uma prática coerente do bom cidadão. Seria imprimir, nesse limiar dos tempos republicanos, reforçar nesses homens elementos de uma prática religiosa no seu dia a dia. A religião seria compreendida como uma reguladora da moralidade desse indivíduo, assim como o exército que desenvolvia o papel da virilidade desses homens.

Nessa via de compreensão, Pierre Bourdieu nos aponta que:

[...] a monopolização da gestão dos bens de salvação por um corpo de especialistas religiosos, socialmente reconhecidos como os detentores exclusivos da competência especifica necessária à produção ou à reprodução de um 'corpus' deliberadamente organizado de conhecimentos secretos (e, portanto raros), a constituição de um campo religioso acompanha a desapropriação objetiva daqueles que dele são excluídos e que se transformam por essa razão em leigos(ou profanos, no duplo sentido do termo) destituídos do capital religioso (enquanto trabalho simbólico acumulado) e reconhecendo a legitimidade desta desapropriação pelo simples fato de que a desconhecem como tal[...]. (BOURDIEU, 1992, p.39.).

Ao pensarmos nessa questão, podemos perceber o quanto a religião era uma fonte de normalização das ações humanas, principalmente, na constituição da representação do conceito de bom cidadão. A religião, nesse caso, estabelece critérios, parâmetros que desencadeavam a percepção acerca das atitudes desse homem, como as demais pessoas da sociedade.

As práticas ratificam a representação da masculinidade, enquanto valorizada socialmente, fator pelo qual os homens são avaliados, pois como seria entendido o que esse homem era para a cidade, dava-se em virtude da forma como ele se relaciona com as estruturas que eram importantes para ratificar o seu papel social. 
[...] os homens, detentores do monopólio dos instrumentos de produção e de reprodução do capital simbólico, visam a assegurar a conservação ou o aumento deste capital: estratégias de fecundidade, estratégias matrimoniais, estratégias educativas, estratégia econômicas, estratégias de sucessão, todas elas orientadas no sentido de transmissão dos poderes e privilégios herdados. (BOURDIEU, 2003b, p. 62.)

Por isso, ao refletir sobre essa questão, Nolasco, aponta que o homem brasileiro, principalmente, no período da República Velha, tinha e devia receber dos demais aprovação como indivíduo de boa estirpe e índole.

A preocupação com a aprovação dos outros e certos puder em se aceitar como é fazem parte tanto da dinâmica subjetiva masculina quanto de um momento vivido elos propagandistas da velha República, em que imperava a concepção de o Brasil não poderia crescer pelas próprias forças naturais: devia formar-se de fora para dentro, devia merecer a aprovação dos outros. (NOLASCO, 1993, p. 95).

Nesse caso, olhamos como não era possível afirmar sua masculinidade apenas pelo órgão sexual, a questão do reconhecimento desse homem também deveria ser compreendida no cotidiano da cidade, pelos outros cidadãos, assim como as estruturas de poder existentes nesse espaço.

A construção de identidades vale-se da matéria-prima fornecida pela história, geográfica, biológica, instituições produtivas e reprodutivas, pela memória coletiva e por fantasias pessoais, pelos aparatos de poder e revelações de cunho religioso. Porém, todos esses materiais são processados pelos indivíduos, grupos sociais e projetos culturais enraizados em sua estrutura social, bem como em sua visão de tempo/espaço [...]. (CASTELLS, 2000, p. 24).

Acerca dessa questão, Manuel Castells afirma, ainda, que embora "[...] as identidades também possam ser formadas a partir de instituições dominantes, somente assumem tal condição quando e se os atores sociais as internalizam, construindo seu significado com base nessa internalização." (CASTELLS, 2000, p. 23).

\section{CONSIDERAÇÕES FINAIS}

Os discursos - advindos dos interlocutores do regime republicano e mesmo da imprensa - estavam voltados a reproduzir os novos ideais para que a Nação ideal, 
assim tão desejada, pudesse se estabelecer como uma verdade. Nesse sentido, voltando nosso olhar para as questões de gênero, principalmente em torno da figura masculina, vamos identificar representações nas quais esse homem deveria ao longo do seu cotidiano manifestar práticas que reforçassem os interesses em relação a esse ideal. Por essa perspectiva, identificamos uma necessidade dos propagadores dos ideais republicanos, principalmente a partir da imprensa, de reforçar acerca dos caminhos que esses homens deveriam seguir, a fim de contribuírem com a premissa ordem e progresso.

Além dessas ideias, os jornais também se tornaram janelas para se buscar salientar o quão se fazia necessário, por parte dos homens, constituir no seu cotidiano o cuidado com a própria honra, entretanto resolvendo tais questões a partir do diálogo, enquanto homens intelectuais. Por essa perspectiva, os comportamentos dos homens pertencentes aos segmentos populares eram vistos como práticas desordeiras, em vista do uso da violência como via para resolver divergências entre eles e outros indivíduos.

Por isso, a pesquisa mostrou que as características que demarcavam os homens vistos como ordeiros, que se enquadravam dentro das máximas pelas quais se representava o homem ideal para a nação, acabavam não dialogando com os demais comportamentos, principalmente aqueles atribuídos aos homens dos segmentos populares, pois mesmo pertencentes ao cotidiano, ancorados com os valores da nova ordem republicana, estes criavam outro percurso para criar o seu conceito de ordem. Nesse compasso, é válido ressaltar o quão as práticas entendidas como ordem e desordem se tornaram balizas para a construção desta cidade da ordem e do progresso.

As masculinidades encontradas foram elas evidenciadas no começo do século $X X$, tanto em Caxias, quanto no restante do país, buscando o diálogo entre as experiências, mas também a singularidade dessa cidade maranhense. Eram homens, que circularam pelas ruas, com performances masculinas que se distanciavam, ou não, dos padrões traçados naquele contexto. 


\section{REFERÊNCIAS}

ALBUQUERQUE JÚNIOR, Durval Muniz. Nordestino: uma invenção do falo; uma

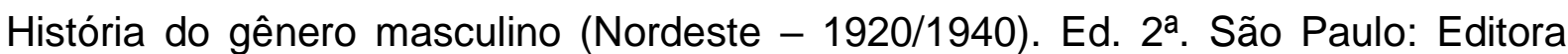
Intermeios, (Coleção Entregêneros), 2013.

ALBURQUERQUE, JUNIOR, Durval Muniz. Nordestino: a invenção do falo - uma história do gênero masculino (Nordeste - 1920/1940), Bagaço, 2003.

ALMEIDA, Miguel Vale de. Senhores de si: Uma interpretação antropológica da masculinidade. Lisboa: Fim de Século, 1995.

BAKHTIN, Mikhail. Marxismo e filosofia da linguagem. São Paulo: Hucitec, 2006.

BARBOSA, Marialva. Imprensa, Poder e Público: os diários do Rio de Janeiro. Intercom - Revista Brasileira de Comunicação. São Paulo, Vol. XX, no 2, pag. 87-102, jul/dez, 1997.

BOURDIEU, Pierre. A dominação masculina. Rio de Janeiro: Bertrand Brasil, 2003.

BOURDIEU, Pierre. A economia das trocas linguísticas: o que falar que dizer. Trad. Sérgio Miceli et all. 2ª Ed. São Paulo: Edusp, 1998.

BOURDIEU, Pierre. A economia das trocas simbólicas. 5 ed. São Paulo: Perspectiva, 1992.

BOURDIEU, Pierre. O poder Simbólico. Rio de Janeiro: Bertrand Brasil, 2002.

BUCHOLDZ, A. P. Diário dos Campos. Ponta Grossa, Editora UEPG, 2007.

BUTLER, Judith. Quadros de guerra: quando a vida é passível de luto. Rio de Janeiro: Civilização Brasileira, 2015.

CAPELATO, Maria Helena. Imprensa e História do Brasil. São Paulo: Contexto/Edusp, 1988. 
CASTELLS, Manuel. O poder da identidade. Tradução de Klauss Brandini Gerhardt. 2 ed. São Paulo: Paz e Terra, 2000.

CHARTIER, Roger. A história Cultural: entre práticas e representações. Lisboa: Difel, s/d, p. 17.

CHARTIER, Roger. Defesa e ilustração da noção de Representação. Fronteiras. v. 13, No 24. p. 169-183, 2011.

CHARTIER, Roger. História Cultural: entre práticas e representações. Lisboa: DIFEL, 2002.

CHARTIER, Roger. O mundo como representação. In: À beira da falésia: a história entre incertezas e inquietude. Trad. Patrícia Chittoni Ramos. Porto Alegre: Ed. Universidade/UFRGS, 2002.

CONNELL, Robert W.; MESSERSCHIMIDT, James W. Masculinidade hegemônica: repensando o conceito. Revista Estudos Feministas, Florianópolis, v. 21, n.1, p. 257, 2013.

COUTINHO, Milson. Caxias das Aldeias Altas: subsídios para sua história. 2. ed. São Luís: Caxias: Prefeitura de Caxias, 2005.

FOUCAULT, Michel. Vigiar e punir: nascimento da prisão. Trad. Raquel Ramalhate. 36 ed. Petrópolis, Rio de Janeiro, Vozes, 2009.

GROSZ, Elizabeth. Corpos reconfigurados. Cadernos Pagu, n. (14) 2000.

JORNAL O PAIZ, 26 de junho de 1904, Ano II, número 75, p.03.

JORNAL GAZETA CAXIENSE, 22 de dezembro de 1893, Ano VII, número 86, p. 02 JORNAL GAZETA CAXIENSE, 01 de janeiro de 1894, Ano VIII, número 89, p. 01 JORNAL GAZETA CAXIENSE, 01 de janeiro de 1894, Ano VIII, número 89, p. 01 
JORNAL GAZETA CAXIENSE, 01 de junho de 1894, Ano VIII, número 131, p. 02. JORNAL GAZETA CAXIENSE, 12 de junho de 1894, Ano VIII, número 136, p. 02. JORNAL GAZETA CAXIENSE, 12 de junho de 1894, Ano VIII, número 136, p. 02. JORNAL GAZETA CAXIENSE, 25 de abril de 1893, Ano VII, número 19, p. 02 LUCA, Tânia Regina de; MARTINS, Ana Luiza. Imprensa e cidade. São Paulo: Editora da UNESP, 2006.

LUCA, Tânia Regina. A história dos, nos e por meio dos periódicos. In: PINSKY, Carla Bassanezi (org.). Fontes Históricas. São Paulo: Contexto, 2005.

NOLASCO, Sócrates Alvares. O mito da masculinidade. Rio de Janeiro: Rocco, 1993.

OLIVEIRA, Pedro Paulo de. A construção social da masculinidade. Belo Horizonte: Editora UFMG, 2004.

OLIVEIRA, Rodrigo Santos de. A relação entre a história e a imprensa, breve história da imprensa e as origens da imprensa no Brasil (1808-1930). Revista Historiæ, Rio Grande, 2 (3): 125-142, 2011.

STEPHANOU, Alexandre Ayub. Censura no Regime Militar e militarização das artes. Porto Alegre: EDIPUCRS, 2001.

Enviado: Novembro, 2020.

Aprovado: Dezembro, 2020. 